\title{
NA TEIA DO CONHECIMENTO: A BIOLOGIA DAS ARANHAS TRABALHADA POR MEIO DO ENSINO POR PROJETOS
}

\author{
João Custódio Fernandes Cardoso ${ }^{1}$ \\ Talita Martins Faria ${ }^{2}$ \\ Tatiana Mordente Clemente ${ }^{3}$ \\ Giuliano Buzá Jacobucci ${ }^{4}$
}

\begin{abstract}
RESUMO: A formação de cidadãos críticos e conscientes relaciona-se com o conhecimento científico e com o estabelecimento de uma postura ambiental desde os primeiros anos escolares. Dessa forma, o ensino das Ciências Naturais é de suma importância no processo educacional de crianças e jovens. Nesse contexto, o presente trabalho relata uma proposta de extensão universitária realizada com alunos do segundo ano do Ensino Fundamental, sob a perspectiva do ensino por meio de projetos. A biologia das aranhas foi o assunto escolhido pelos próprios alunos, devido à curiosidade que os mesmos apresentavam sobre o referido grupo de seres vivos. Diversos recursos didáticos foram utilizados no trabalho, incluindo vídeos, dramatizações, jogos didáticos, conversas em grupo, brincadeiras e atividades práticas, buscando sempre frisar a relação do ser humano com a natureza e os demais seres vivos. No decorrer do projeto, foi possível observar a construção do conhecimento científico e o desenvolvimento do processo de ensino e aprendizagem das crianças, bem como a noção da importância do papel desempenhado pelas aranhas no ambiente. Os alunos participaram ativamente das atividades, demonstrando grande envolvimento, uma vez que sempre levavam novas curiosidades, dúvidas e comentários, sendo, assim, agentes do próprio aprendizado.
\end{abstract}

PALAVRAS-CHAVE: Ensino de Ciências. Ensino de Zoologia. Estratégias didáticas.

On the web of knowledge: the spider's biology worked through teaching by projects

\begin{abstract}
The formation of critical and aware citizens is related to scientific knowledge and the establishment of an environmental stance since the early school years. Thus, the teaching of Natural Sciences is extremely important in the educational process of children and the youth. In this context, this paper describes a proposal of university extension performed with the second year of elementary school, from the perspective of Teaching by means of Projects. The biology of spiders was the subject chosen by the students, due to the curiosity that they had on this group of organisms. Several teaching resources were used at work including videos, dramas, educational games, group conversations and practical activities, always trying to emphasize the relationship of humans with nature and other living beings. During the project it was possible to observe the construction of scientific knowledge and development of teaching and learning of children, as well as the notion of the importance of the role of spiders in the environment. Students actively participated in activities demonstrating high involvement, since they always expressed new curiosities, questions and comments, demonstrating that they are agents of their own learning.

\footnotetext{
${ }^{1}$ Mestrando em Ecologia e Conservação de Recursos Naturais pela Universidade Federal de Uberlândia (juaocustodio@hotmail.com).

${ }^{2}$ Mestranda na Faculdade de Educação da Universidade Federal de Uberlândia (talitamartins bio@yahoo.com).

${ }^{3}$ Doutoranda em Microbiologia e Imunologia pela Universidade Federal de São Paulo (tatianamordente@yahoo.com.br).

${ }^{4}$ Doutor em Ecologia pela Universidade Estadual de Campinas, professor adjunto no curso de Ciências Biológicas do Instituto de Biologia da

Universidade Federal de Uberlândia, tutor do PET/Biologia (jacobucci@inbio.ufu.br).
} 
KEYWORDS: Science Education. Zoology Education. Teaching strategies.

\section{INTRODUÇÃO}

A formação de um cidadão crítico exige sua inserção em uma sociedade em que o conhecimento científico e tecnológico é cada vez mais valorizado. Neste sentido, um dos objetivos das Ciências Naturais é o de colaborar para a compreensão do mundo e suas transformações, situando o ser humano como indivíduo participativo e parte integrante do universo (BRASIL, 1996).

Estudos realizados em diversos países mostram a importância de o conhecimento científico ser trabalhado logo nos anos iniciais do processo educacional, uma vez que, inicialmente, os estudantes apreciamaciência, mas nodecorrerde suavidaescolarcomeçam a perdero interesse(GARDNER, 1985).

A inserção de tal conhecimento logo nos primórdios da escolarização é possível, já que, mesmo crianças, os alunos são capazes de construir explicações e desenvolver ideias lógicas acerca dos fenômenos científicos (KRASILCHIK, 1988). Entretanto, o processo educativo inicial deve ser feito de maneira parcimoniosa. O ensino de Ciências, por exemplo, desperta interesse nos alunos quando os ajuda a compreenderem seu próprio mundo. Obviamente, isto quer dizer que, para que os modelos científicos que lhes são impostos tenham sentido, tais padrões deveriam relacionar-se, de alguma forma, à história e ao mundo destes alunos (BLACK; ATKIN, 1996).

A fim de facilitar o ensino de Ciências, são elaborados modelos de ensino, ou seja, representações desenvolvidas visando ajudar os estudantes a entenderem algum aspecto do que se deseja ensinar (GILBERT; BOULTER; ELMER, 2000). Nota-se, então, o desafio que se coloca diante das instituições escolares: a intensa busca por alternativas de ensino mais abertas e próximas dos alunos. Diante disso, o ensino por projetos tem sido uma alternativa frequentemente presente no contexto escolar, refletindo as intenções de uma educação mais ampla, contextualizada e libertadora (OLIVEIRA; VENTURA, 2005).

Os projetos são propostas desenvolvidas em equipe, cujo objetivo é propiciar a compreensão de uma dada situação ou fato. Dessa forma, o ponto de partida deve se dar por meio da problematização de algum tema, que pode ser sugerido pelos alunos ou proposto pelo docente, cujo enfrentamento vai requerer a organização de atividades de aprendizagem, que os alunos ajudam a planejar (HANSEN; PINHEIRO, 2005). Ao elaborar um planejamento, é importante considerar que as atividades precisam ter significado e sentido para o aluno. Além disso, vale ressaltar que, atualmente, como alternativa de ensino e aprendizagem, os projetos podem ser utilizados para se trabalhar de acordo com os princípios de interdisciplinaridade e contextualização (MELLO; DALLAN; GRELLET, 2004).

O ensino por projetos, como alternativa para o ensino tradicional das Ciências Naturais, pode ocorrer de muitas maneiras, tanto envolvendo o professor, um grupode professores, quanto partindode uma parceria da escola comalgum elemento da comunidade externa, pormeio, por exemplo, da extensão universitária. 
Diversos tipos de atividades de extensão são desenvolvidos pelo grupo PET/Biologia-UFU ${ }^{5}$ em diferentes ambientes. A extensão tem grande importância para o desenvolvimento tanto da sociedade quanto da universidade. Isso porque funciona como uma via de mão dupla, uma vez que os conhecimentos produzidos e trabalhados na academia são repassados para a sociedade pelos extensionistas, que adquirem vivências e conhecimentos em seu contato com o público não acadêmico (SERRANO, 2006).

Dentre os diferentes espaços em que o PET/Biologia realiza atividades extensionistas, estão englobadas as instituições escolares da Educação Básica. Uma dessas atividades ocorreu em uma escola privada da cidade de Uberlândia/MG. Membros do corpo docente da escola já conheciam o trabalho do grupo, devido a outras atividades já realizadas, nessa e em outras instituições de ensino, e convidaram o mesmo para o desenvolvimento de um projeto com 18 alunos do $2^{\circ}$ ano do Ensino Fundamental, com idades entre cinco e seis anos. $\mathrm{O}$ tema a ser trabalhado foi definido pelos próprios alunos, antes mesmo de o convite ser feito. Eles optaram por estudar um pouco mais sobre as aranhas, já que tinham curiosidade pelo assunto e contato com representantes desse grupo de organismos, tanto no cotidiano quanto por meio da mídia.

\section{PROPOSTA METODOLÓGICA}

Ao investigar o tema a ser tratado em uma classe, pauta-seno conhecimento já existente, estabelecendo uma rede de ideias acerca do assunto em questão, selecionando quais noções pretende-se trabalhar com os alunos. Assim, como sugerido por Labinas, Calil e Ayoama (2010), a negociação do tema visa sanar os interesses individuais em direção a um fim comum. Desta maneira, os projetos propõem mais do que uma renovação de atividades, mas também uma mudança na postura pedagógica.

Os projetos na escola podem ser vistos como uma atividade privilegiada para se trabalhar determinada situação, fato ou tema de forma interdisciplinar e contextualizada, por meio de atividades que sejam significativas para o aluno (MELLO; DALLAN; GRELLET, 2004). Neste sentido, a experiência, aqui relatada, caracterizou-se como uma forma de ensino baseada em projetos, pois envolveu a elaboração e execução de atividades com os alunos, visando ampliar o seu conhecimento acerca de uma temática específica.

O projeto teve duração de seis meses e foi realizado em 2009, sendo composto por treze encontros, sempre às sextas-feiras úteis. Cada encontro teve duração de $1 \mathrm{~h} 40 \mathrm{~min}$, contando com a participação de dois mediadores do grupo PET/Biologia e com o apoio da professora regente da turma, que esteve presente no decorrer de todo o projeto. Além de auxiliar os mediadores no que diz respeito à transposição didática dos conteúdos, a professora também permitiu que o grupo tivesse total liberdade na elaboração e execução das atividades.

Como referencial teórico específico, os petianos utilizaram dois livros de Ensino Superior: "Ecologia e Comportamento de Aranhas" e "Biology of spiders". As informações retiradas desses livros foram

\footnotetext{
${ }^{5}$ O Programa de Educação Tutorial do curso de Ciências Biológicas da Universidade Federal de Uberlândia (PET/Biologia - UFU) é composto por doze alunos de graduação que, orientados por um docente tutor, desenvolvem atividades que contemplam os três pilares regentes da universidade brasileira: ensino, pesquisa e extensão.
} 
adaptadas pelos mediadores para serem passadas às crianças envolvidas no projeto. O grupo lançou mão de diversas estratégias e recursos didáticos, visando aumentar o interesse e a curiosidade dos alunos.

\section{ESTRATÉGIAS DIDÁTICAS}

Os conteúdos foram trabalhados a partir das seguintes estratégias didáticas:

a. Avaliação diagnóstica - no primeiro encontro, por meio de uma conversa, o grupo objetivou conhecer as expectativas dos alunos em relação ao projeto, seus anseios acerca do tema e conhecimentos prévios sobre o assunto. Este primeiro contato, antes de iniciar um novo assunto, é de extrema relevância, já que permite diagnosticar os conhecimentos dos alunos sobre os conteúdos previstos para iniciar uma unidade de ensino, uma disciplina ou um curso (SANT'ANNA, 1998). Em outras ocasiões, esse tipo de avaliação também foi utilizado, pois, por meio de rodas de discussão, o grupo pode observar o quanto os alunos sabiam a respeito dos temas trabalhados, quais eram seus questionamentos e opiniões em relação aos conteúdos e, assim, nortear as atividades de forma a sanar as dúvidas e trabalhar as dificuldades. Cada encontro contou com um espaço dedicado a anotações de comentários e questionamentos para que os mesmos fossem retomados posteriormente, frisando aspectos relevantes.

b. Dramatizações - foram utilizadas para abordar temas relacionados à biologia das aranhas, como forma de desenvolver atividades divertidas e que, ao mesmo tempo, promovessem uma interação entre os alunos. Como a dramatização envolve o movimento físico, ela pode ser utilizada para ajudar a explicar conceitos abstratos (WARD; HEWLETT; RODEN, 2010). Além de exigir movimento corporal, ela gera necessidade de interação e cooperação e estimula os alunos a se comunicarem por meio de uma linguagem científica, pois eles próprios são protagonistas de uma situação que envolve o conteúdo trabalhado (TAYLOR, 1997 apud WARD; HEWLETT; RODEN, 2010).

c. Jogos didáticos - estes recursos foram utilizados, principalmente, como forma de revisar conteúdos e mostraram-se muito eficientes, uma vez que estas atividades sempre traziam algum desafio para os alunos, o que despertava interesse pela atividade proposta. Conforme discutido por Campos, Bortoloto e Felício (2003), a utilização do jogo é relevante por aliar os aspectos lúdicos aos cognitivos. Sendo assim, pode-se entender que o jogo é uma importante estratégia para o ensino e a aprendizagem de conceitos mais abstratos, pois favorece a motivação interna, o raciocínio, a argumentação, a interação entre alunos e entre professores e alunos. Sendo assim, o jogo didático é responsável por desenvolver a cognição, a afetividade, as funções sensório-motoras e a área social como, por exemplo, as relações entre os alunos e a percepção das regras (KISHIMOTO, 2000; CAMPOS; BORTOLO; FELÍCIO, 2003). Além disso, os jogos oferecem oportunidades para os educandos aprenderem conteúdos relacionados à ciência e à linguagem associada, de um modo interessante (WARD; HEWLETT; RODEN, 2010). No entanto, para que esta estratégia seja utilizada de forma eficiente, é necessário que o jogo seja planejado para 
ser motivador e divertido, mantendo os alunos entretidos e concentrados na atividade. Neste sentido, os mediadores conseguiram seguir o planejamento e manter a atividade controlada para que os objetivos propostos com o uso destes recursos fossem alcançados.

d. Produções escritas e desenhos - foram utilizados na forma de exercícios, seja para representar conhecimentos prévios sobre o assunto ou como forma de avaliar o quanto os alunos haviam compreendido sobre o conteúdo trabalhado. Para Almeida (2004), o desenho pode ser considerado, durante as fases iniciais de escolarização, a atividade que melhor demonstra o desempenho dos estudantes, pois exige observação por parte dos discentes e, ao mesmo tempo, possibilita a organização e o registro de ideias, uma vez que trabalha com a análise e síntese de informações.

e. Aulas práticas - para que os alunos pudessem observar em espécimes reais, bem como as estruturas estudadas e observadas em fotos e esquemas. Foram utilizados animais fixados cedidos pela Universidade Federal de Uberlândia. Hoering e Pereira (2004) afirmam que, ao visualizar o objeto de seu estudo, o aluno entende melhor o assunto, pois o que está sendo observado pode ser manipulado e tocado, o que permite que da observação concreta possa se construir um conceito e não apenas imaginá-lo.

f. Tecnologias da Informação e da Comunicação (TIC's) - foram utilizadas para melhor ilustrar os temas trabalhados. Neste caso, como o tema do projeto foi bastante específico, estes recursos foram de extrema importância, pois imagens sobre aspectos biológicos das aranhas são raros em livros didáticos e revistas de divulgação. Dessa forma, o grupo selecionou imagens e esquemas em sites na internet e em livros voltados para o Ensino Superior e os apresentou sob a forma de slides em projetor multimídia. Com isso, foi possível fazer explicações de forma mais clara e dinâmica acerca dos assuntos trabalhados, neste caso, morfologia, ecologia e diversidade de aranhas.

\section{ATIVIDADES REALIZADAS}

a. Teia de curiosidades: neste encontro, o grupo objetivou, por meio de uma conversa informal com os alunos, compreender o porquê de eles optarem por estudar as aranhas, quais eram suas dúvidas, expectativas, conhecimentos prévios sobre o assunto e o que lhes interessava saber. As discussões nortearam a elaboração das atividades a serem desenvolvidas ao longo dos demais encontros. Alguns questionamentos foram particularmente importantes para nortear as ações do projeto. Dentre estes, pode-se citar: "Por que a teia é tão grudenta?", “A aranha pica ou morde?", "A teia é cocô?”. Foi possível perceber, por meio de afirmações feitas, que alguns alunos apresentavam noções de ecologia como, por exemplo, "As aranhas são importantes porque comem insetos". E também conheciam um pouco a respeito da biologia destes animais como pode ser observado na resposta à pergunta "Por que a teia é tão grudenta?": "Para grudar os insetos". 
b. Características gerais das aranhas: este foi o primeiro tema a ser trabalhado no projeto e versou sobre assuntos como a diversidade dos aracnídeos, locais onde estes animais ocorrem e características que os identificam e os diferenciam dos insetos. Neste encontro, as crianças tiveram muitos questionamentos e o grupo foi esclarecendo dúvidas como: "Onde fica o coração da aranha?" e "A aranha tem esqueleto?".

Para trabalhar esta temática, foram apresentadas imagens de diferentes espécies de aranhas, utilizando projetor multimídia e também um quebra-cabeça que consistia na imagem de uma aranha caranguejeira (pertencente à família Theraphosidae) (Figura 1). Os alunos foram divididos em três grupos, cada qual responsável pela montagem do seu. A montagem do quebra-cabeça foi completada com sucesso pelas crianças e em um curto espaço de tempo, fato que fez com que o grupo percebesse que deveria elaborar atividades mais desafiadoras e com um nível de dificuldade mais elevado.

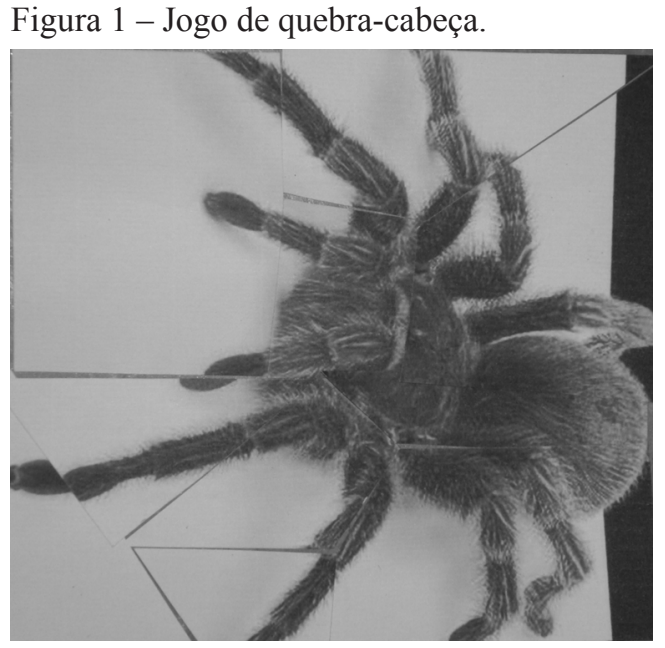

Fonte: Acervo dos autores.

Durante a discussão, ao final do encontro, as crianças fizeram vários comentários sobre experiências que já tiveram com aranhas, compartilhando informações que haviam pesquisado, embora nem todas estivessem cientificamente corretas. Um dos alunos, por exemplo, disse ter lido na internet que a aranha caranguejeira tem peçonha mais poderosa que a da cascavel, o que é incorreto. Como Ferraresi e colaboradores (2009) destacaram, embora a pesquisa seja importante, é essencial verificar a origem da informação para seu manejo seguro, sendo, por isso, necessário instruir os estudantes acerca dos meios corretos para verificar a credibilidade da informação acessada. Dessa forma, o grupo aproveitou esta oportunidade para chamar a atenção dos alunos para as fontes de pesquisa que eles estavam utilizando e as precauções que se deve ter ao buscar essas informações.

c. Anatomia geral das aranhas: neste encontro, foi feito um estudo a fim de apresentar aos alunos estruturas e partes do corpo destes animais. Para tanto, o grupo utilizou esquemas do corpo de uma aranha mostrando estruturas como: cefalotórax, abdome, olhos e pernas. Utilizou, também, fotos de diferentes espécies, para que eles pudessem visualizar as estruturas vistas nos esquemas. As crianças demonstraram facilidade em identificar as estruturas e, embora ainda tivessem algumas dúvidas em relação ao tema, 
estas foram esclarecidas com novas explicações. Durante a atividade, os mediadores foram questionados acerca da ausência do nome científico das aranhas apresentadas nas fotos, o que chamou atenção para a necessidade de inserir o nome das espécies apresentadas nos encontros seguintes. Como forma de avaliação, foram distribuídas folhas com o desenho de uma aranha para que os nomes das estruturas fossem indicados (Figura 2)

Figura 2 - Realização da atividade de nomear as estruturas anatômicas indicadas.

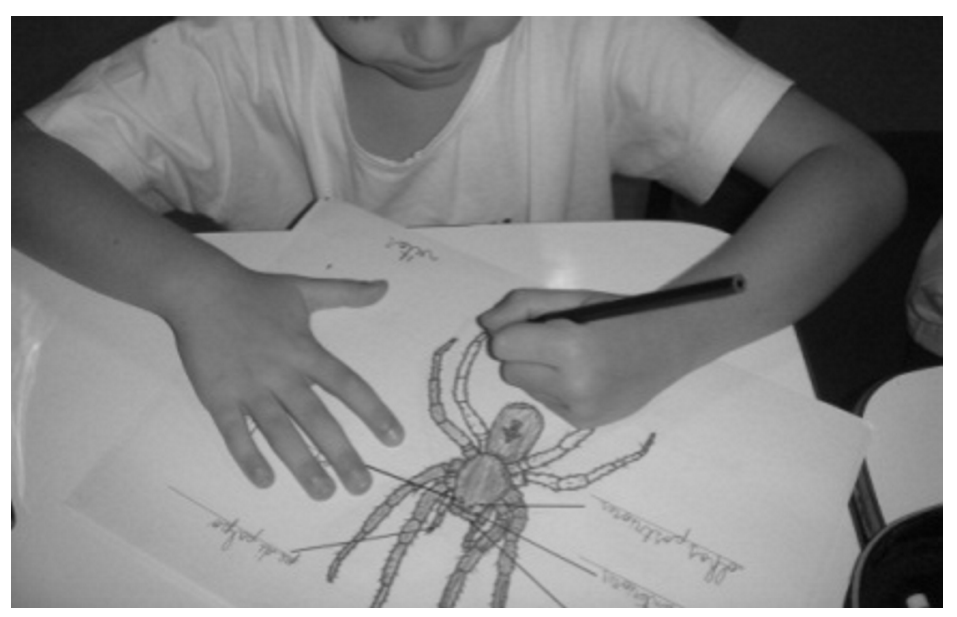

Fonte: Acervo dos autores.

d. Estruturas sensoriais das aranhas: este encontro teve como objetivo apresentar as estruturas sensoriais das aranhas e explicar como ocorre a comunicação entre estes animais. O grupo utilizou ilustrações e também espécimes fixados de caranguejeira, viúva negra (Latrodectus sp., Theridiidae) e armadeira (Phoneutria nigriventer, Ctenidae) para que os alunos pudessem observar as estruturas anatômicas trabalhadas no encontro anterior e, também, aquelas relacionadas à comunicação e percepção do ambiente.

A utilização de imagens ampliadas dos órgãos estudados foi um recurso bastante eficiente, pois permitiu que as estruturas fossem observadas de forma facilitada, além de despertar a curiosidade das crianças em relação a outras que não aquelas já vistas. Segundo Martins Gouvêa e Piccinini (2005), além da indiscutível importância das figuras como recursos para a visualização, uma vez que são mais facilmente lembradas do que suas correspondentes representações verbais, elas também desempenham um papel fundamental na constituição das ideias científicas e na sua conceitualização. Este contato direto com as aranhas estimulou os alunos a fazerem mais questionamentos a respeito do funcionamento das estruturas anteriormente apresentadas.

e. Como as aranhas convivem entre si: ao trabalhar este tema, objetivou-se esclarecer aos alunos como estes animais comportam-se frente a outros indivíduos, sejam da mesma espécie ou de outras. Para explicar o assunto, foi feita uma dramatização, na qual as crianças seriam as aranhas, um dos mediadores seria um menino que estaria muito interessado em observar a interação destes animais e o outro seria o narrador. Foram formados três grupos de aranhas de diferentes espécies: caranguejeira, aranha marrom 
(Loxosceles sp., Sicariidae) e aranhas sociais (Anelosimus sp., Theridiidae), diferenciados por fantasias de cores distintas. Durante o teatro, o menino fazia diversos experimentos, colocando os indivíduos da mesma espécie juntos e, depois, espécies diferentes juntas a fim de observar o que acontecia em cada caso, enquanto o narrador explicava o que acontecia.

A utilização do teatro no contexto escolar constitui-se em uma atividade que pode auxiliar na assimilação dos conteúdos científicos, uma vez que a criança tem a oportunidade de se transformar no personagem, vivendo a realidade estudada e compreendendo melhor os significados que eles representam (LORENZETTI; DELIZOICOV, 2001). Assim, esta atividade mostrou-se como uma estratégia adequada para demonstrar como a maioria das aranhas tem hábito solitário, ou seja, quando elas se encontram em um mesmo local, geralmente ocorrem conflitos ou fugas. Este fato despertou a curiosidade dos alunos, que levantaram diversos questionamentos, como por exemplo: "Se uma aranha caranguejeira encontrar uma aranha marrom, quem ganha?", "Se as aranhas sociais se unirem numa briga contra uma aranha marrom, quem vence?".

A atividade foi considerada satisfatória, uma vez que os alunos participaram ativamente da mesma, demonstrando interesse pela temática trabalhada. Além disso, as crianças compreenderam que as aranhas são, em sua maioria, animais solitários e que interagem entre si apenas em determinados momentos.

f. Habitação e alimentação das aranhas: este assunto foi abordado, inicialmente, por meio de uma roda de discussão, na qual foram levantadas questões, pelos mediadores e pelos alunos, a respeito do tema. Em seguida, as crianças desenharam em folha sulfite o que elas sabiam sobre a habitação e a alimentação das aranhas. Feito isso, os mediadores apresentaram slides com figuras e informações e fizeram uma explicação do conteúdo proposto. Por fim, as crianças novamente desenharam sobre o tema em questão e, assim, foi possível observar o que havia mudado em seus conceitos depois da explicação (Figura 3).

Figura 3 - Desenhos feitos pelos alunos sobre alimentação e habitação das aranhas.

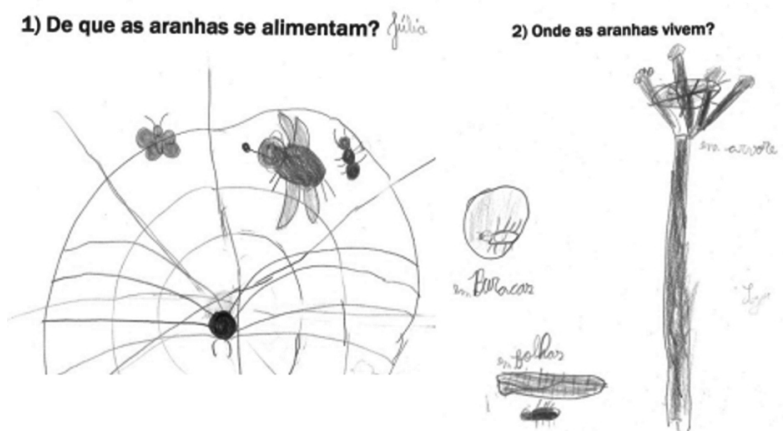

Fonte: Acervo dos autores. 
Foi possível constatar, por meio dos desenhos feitos pelos alunos, que a maior parte do conhecimento prévio que estes apresentavam sobre a alimentação das aranhas estava relacionado ao hábito insetívoro desses animais, havendo desconhecimento de outros hábitos alimentares. Quanto à habitação, de maneira geral, as crianças manifestaram um amplo conhecimento, inclusive em relação ao hábito semiaquático de algumas espécies. Atividades dessa natureza são válidas, pois permitem uma interação entre o novo conhecimento e o já existente, sendo que ambos se modificam, pois as noções prévias funcionam como base para a atribuição de significados à nova informação. Neste processo dinâmico, o conhecimento vai sendo construído (MOREIRA, 1997).

Vale ressaltar que as crianças ficaram impressionadas ao saber que certas aranhas têm hábitos canibalísticos e que outras, como as caranguejeiras e, entre estas, a aranha Golias (Theraphosa blondi, Theraphosidae), alimentam-se de pequenos roedores e até mesmo de pássaros. Houve indagações acerca da necessidade de o alimento ser liquefeito, sendo, então, elucidado que as aranhas não possuem dentes e não mastigam, ingerindo o alimento já na forma líquida. Quanto à habitação, acrescentou-se às crianças o conceito de camuflagem e foram reforçadas outras formas de habitação, sobre as quais os alunos já expressavam um bom domínio.

g. Mecanismo de produção da teia: um assunto interessante relacionado às aranhas é a construção da teia. Devido a isso, um dos encontros foi dedicado a esta temática, com a finalidade de explicar aos alunos como as aranhas produzem sua teia, por qual motivo elas a fazem e por que nem todas a constroem. Neste encontro, inicialmente, foi feita uma explicação teórica utilizando imagens que mostrassem a sequência dos processos que as aranhas utilizam para confeccionarem suas teias, as glândulas responsáveis pela sua produção e, também, os diferentes tipos de teia. Em seguida, foi exibido um vídeo gravado por uma das mediadoras, que registrou o momento em que uma aranha fabricava sua teia.

Os vídeos relacionam-se a um contexto de lazer e entretenimento, que é imperceptivelmente passado à sala de aula. Dessa forma, na concepção dos alunos, assistir a um vídeo, significa descansar das aulas, o que modifica a postura e as expectativas destes. É importante que essa expectativa positiva seja aproveitada para atrair o aluno para os assuntos a serem trabalhados. Ao mesmo tempo, é preciso atentar para o estabelecimento de novas pontes entre este recurso e as outras dinâmicas da aula (MORÁN, 1995). Com a exibição do vídeo, os alunos compreenderam melhor os mecanismos pelos quais as aranhas confeccionam suas teias, sanando as dúvidas que ficaram na exposição teórica.

Para encerrar o encontro, foi feita uma atividade com os alunos, na qual eles deveriam construir uma teia gigante utilizando barbante (Figura 4). Esta atividade foi produtiva, uma vez que as crianças se divertiram e ainda puderam compreender o quão complexa é a estrutura da teia construída pelas aranhas. 
Figura 4 - Construção da teia gigante de barbante.

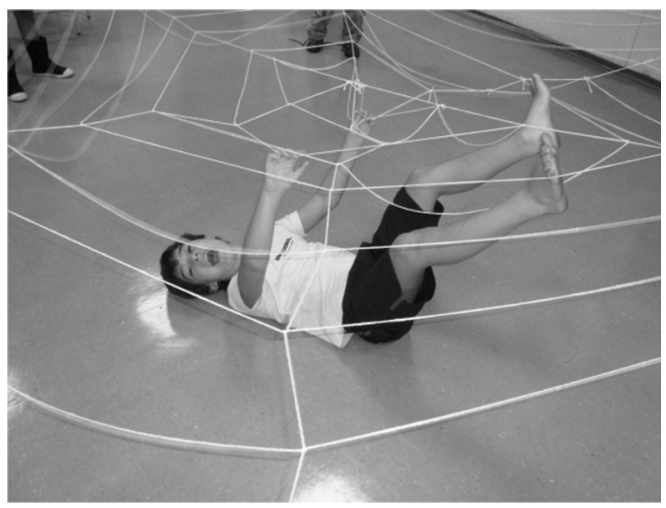

Fonte: Acervo dos autores.

h. Comportamento reprodutivo das aranhas: neste encontro, buscou-se explicar aos alunos como ocorrem os processos de corte e cópula das aranhas, bem como se dão os cuidados parentais destes animais. Inicialmente, foi feita uma explanação acerca dos conceitos referentes à reprodução. Em seguida, utilizando slides com várias imagens, explicou-se como se dá a cópula em aranhas e o processo de oviposição da fêmea.

As crianças mostraram-se muito interessadas, principalmente em relação aos cuidados parentais da fêmea. Ao final da apresentação, alguns alunos disseram terem visto ootecas embaixo da bancada da secretaria. Todos foram ver e realmente eram várias ootecas e, com isso, as crianças puderam comprovar sua existência, sua aparência e suas funções. Foi um momento de elucidação do conteúdo abordado. Este fato revelou o quanto os alunos estavam interessados em conhecer estes animais, pois a busca por esclarecimentos e novidades não se restringia somente às atividades realizadas com o grupo PET em sala de aula, mas se estendia ao seu cotidiano.

i. Interação das aranhas com os seres humanos: primeiramente, houve uma explanação aos alunos por meio de slides. Foram apresentados alguns casos de acidentes com aranhas, os locais de maior ocorrência e as principais espécies envolvidas. As espécies mais citadas foram: aranha marrom, viúva negra e armadeira. Foi feita, ainda, uma comparação entre o perigo apresentado pela peçonha destas com o de outras aranhas, como a caranguejeira, por exemplo, que apesar de muito amedrontar as pessoas, apresenta pouco perigo aos seres humanos.

Em seguida, foram abordados os benefícios e malefícios da interação aranha-homem, tanto para o homem quanto para as aranhas. Nessa parte, foram tratadas questões como a utilização desses animais para estudos em laboratórios, sua importância no ambiente ecologicamente equilibrado e utilização destes bichos como animais de estimação, ressaltando os perigos que esta prática ocasiona e os problemas que podem oferecer para pessoas e aranhas. Dentre os malefícios, foram abordados os acidentes aracnológicos, quais medidas podem ser adotadas para evitá-los, os efeitos que diferentes peçonhas podem ocasionar em humanos, como são tratadas pessoas picadas por aranhas e, por fim, o que deve e o que não deve ser feito na ocorrência de um acidente com uma aranha. A aracnofobia também 
foi citada e os alunos mostraram-se bastante interessados na mesma, sendo que quatro crianças disseram por elas mesmas serem aracnofóbicas. Essa parte foi importante, pois foi possível frisar que não há necessidade de ter medo de aranhas, mas, sim, precaução para evitar acidentes e, para isso, faz-se necessário conhecer os hábitos desses animais.

Ao final, foi planejada uma atividade na qual os alunos deveriam marcar no desenho entregue (Figura 5) onde poderia haver aranhas e também escrever por que elas estariam naqueles locais, além das possíveis medidas para redução da quantidade desses animais na casa, com o intuito de se evitar acidentes. As crianças gostaram bastante do método utilizado e marcaram os lugares corretos, apresentando alternativas viáveis para diminuição de aranhas em habitações humanas.

Figura 5 - Atividade "Onde as aranhas podem se esconder?".

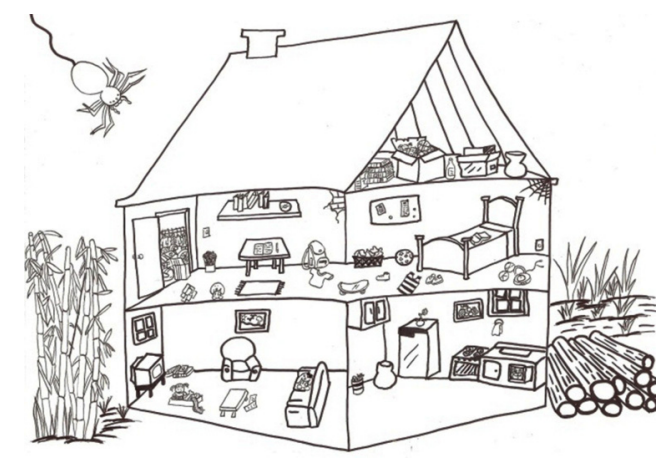

Fonte: Acervo dos autores.

j. Jogo de revisão: após o período de férias dos alunos, foi feita uma revisão de todo o conteúdo abordado até aquele momento, utilizando-se, para isso, um jogo de tabuleiro gigante (Figura 6) elaborado pelos próprios mediadores. Antes de iniciar o jogo, todas as regras foram passadas aos alunos, que foram divididos em duplas. A dupla deveria jogar um dado gigante para determinar o número de casas a serem avançadas e isto só poderia ser feito se os jogadores acertassem a resposta da pergunta a eles direcionada. Caso a dupla errasse a resposta, ela deveria retornar até a casa onde estava e a resposta correta era dita e comentada, isso para que todos pudessem ter contato com a mesma.

Figura 6 - Jogo de tabuleiro.

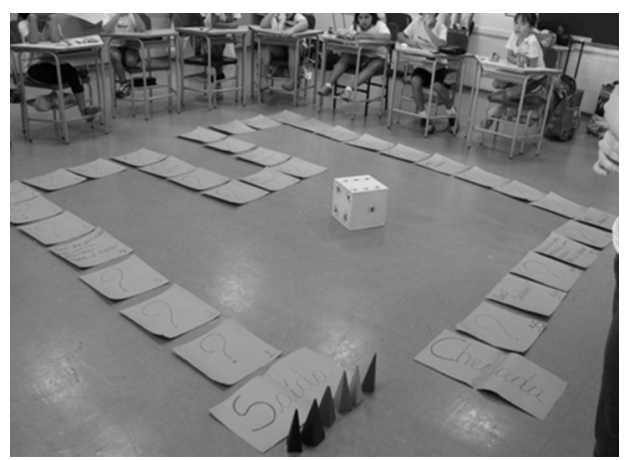

Fonte: Acervo dos autores. 
A realização do jogo foi apropriada, uma vez que as crianças demonstraram interesse, participando ativamente da proposta. Quase todas as perguntas foram respondidas corretamente, mostrando que os alunos conseguiram lembrar grande parte dos conteúdos que foram trabalhados nos encontros anteriores, o que significa que, mesmo que eles tenham estudado os assuntos já há algum tempo, estes não foram esquecidos. $\mathrm{O}$ entusiasmo demonstrado foi notório quando, por exemplo, caíam em um espaço onde estava escrito: "Você foi picado por uma aranha! Fique uma rodada sem jogar", ou mesmo quando paravam em um espaço onde havia um "Você sabia?", e ficavam surpresos em saber que uma aranha caranguejeira pode chegar a viver até vinte anos.

O jogo pedagógico ou didático distingue-se do material pedagógico, pois contém o aspecto lúdico e é elaborado com o objetivo de propiciar determinadas aprendizagens específicas (CUNHA, 1994). Ele é utilizado para atingir determinados objetivos pedagógicos, sendo uma alternativa válida para melhorar o desempenho dos alunos nos conteúdos que se quer tratar (GOMES; FRIEDRICH, 2001). Como o encontro visou à revisão do conteúdo trabalhado durante o projeto no primeiro semestre, a estratégia do jogo foi viável, pois por meio dela foi possível aplicar questões adequadas e interessantes para que os alunos recordassem os conceitos e denominações que já haviam estudado.

k. A importância das aranhas: animais que levam má fama, como é o caso das aranhas, fazem com que tal reputação exerça uma influência negativa na imagem que as pessoas constroem em relação a estes seres. Desse modo, é difícil convencer ouvintes leigos no assunto que tais animais possuem sua importância. Isso pode ser observado no encontro referente ao tema "Interação das aranhas com os seres humanos", no qual foram abordados também os benefícios das aranhas, e, apesar de os alunos terem demonstrado compreender, eles ainda estavam ligeiramente relutantes em enxergar o fato de as aranhas serem benéficas ao ser humano.

Ao longo do projeto, e neste encontro de forma mais aprofundada, o grupo buscou ressaltar a importância destes animais, mostrando que todos os seres têm sua função ecológica na natureza. Sendo assim, não existem organismos "bons" ou "maus", mas sim seres que desempenham papéis diferentes que ora agem contra, ora a favor dos interesses do homem (LABINAS; CALIL; AYOAMA, 2010). Foi ressaltado que, mesmo que alguns grupos de organismos (como as aranhas) pareçam contrariar os interesses humanos, eles exercem funções salutares no equilíbrio do ambiente e que este ambiente equilibrado é, por si só, um grande benefício à manutenção da vida sadia dos seres humanos.

A princípio, houve uma conversa na qual algumas questões foram levantadas pelos mediadores, como: quais as possíveis importâncias que as aranhas têm para o homem nas diversas áreas do conhecimento, como a médica e a ecológica, por exemplo, e o que aconteceria se todas as aranhas desaparecessem. Em seguida, foram apresentadas aos alunos algumas imagens sobre a importância destes animais. Por meio delas, foi possível mostrar às crianças que as aranhas têm importância médico-econômica, na produção de fármacos e fibras superresistentes inspiradas na teia, por exemplo. Os alunos tiveram muitos questionamentos sobre a aplicação das aranhas na área médica e ficaram 
bastante entusiasmados com o fato de que a peçonha desses animais pode ser usada na produção de soros, entre outros. A importância ambiental das aranhas foi amplamente trabalhada, associando, de modo implícito, a relevância que estes organismos têm no equilíbrio ecológico, nas interações ecológicas, na cadeia alimentar e desempenhando papéis, como espécies pioneiras importantes, na colonização de ambientes degradados.

Com o objetivo de frisar os aspectos ambientais que envolvem as aranhas, foi proposta uma dramatização sobre cadeia alimentar, simulando os conceitos mostrados na apresentação, utilizando a teia confeccionada no encontro "Mecanismo de produção da teia". Nesse teatro, cada aluno representou o papel de um animal em um ecossistema. A grande teia de barbante foi estendida e os mediadores indicavam o que cada personagem deveria fazer. Primeiramente, foi simulada uma situação natural, na qual um aluno representando um mosquito, por exemplo, caía na teia da aranha, que era representada por outra criança. Assim, os discentes foram guiados em direção ao que deveria ser feito. Nesse caso, a aranha inoculava a peçonha e predava o mosquito. Em seguida, a aranha era predada por uma ave, por exemplo. Também foi feita a situação inversa, na qual uma ave de menor porte poderia ser predada pela aranha. Ressaltamos que essa era uma relação de equilíbrio na natureza, uma vez que cada um adquiria seu alimento, pois ele estava disponível, e que o ambiente preservado é importante na vida do homem.

Em seguida, a situação foi mudada e a aranha foi eliminada do cenário. Os alunos entenderam perfeitamente que a população de mosquitos iria aumentar, pois não havia mais o predador natural desses insetos no ambiente. Para exemplificar que a grande população de mosquitos é prejudicial ao homem, eles foram relacionados à transmissão de doenças. Obviamente, ressaltamos que os mosquitos, assim como as aranhas e todos os outros animais, plantas e microrganismos têm sua importância dentro do ambiente equilibrado.

Depois disso, o teatro foi refeito várias vezes, sempre trocando os alunos que representavam os diferentes personagens como aranhas, aves, insetos, entre outros. Esta foi uma maneira dinâmica e divertida com a qual os alunos se envolveram bastante e aprenderam muito, pois sugeriam novos personagens, novas situações e respondiam perfeitamente o que ocorreria nas cenas futuras.

Ainda nesse encontro foi proposto um jogo da memória, abordando todos os temas tratados até então. As crianças se organizaram em um círculo e as cartas foram colocadas no centro da roda. $\mathrm{O}$ aluno deveria falar sobre o assunto que a figura representava quando tirasse duas imagens iguais. Durante o desenvolvimento do jogo, foi possível perceber que os alunos se lembravam da maioria dos encontros e dos conceitos abordados.

1. A fisiologia da inoculação da peçonha: inicialmente, foi feita uma roda com as crianças a fim de recordar os assuntos estudados no encontro "A relação das aranhas com o homem", uma vez que este tema tem bastante relevância. Nessa etapa, todas as perguntas foram respondidas perfeitamente pelos alunos, fato que mostrou que eles entenderam 
os aspectos tratados. Em seguida, o conteúdo do presente encontro foi apresentado com a utilização de projetor multimídia, a partir do qual foram explicados os efeitos das diferentes peçonhas, como ocorre a liberação das mesmas, quais as partes integrantes das quelíceras e como estas estruturas são internamente. Bexigas foram utilizadas para ilustrar o funcionamento da glândula de peçonha, estabelecendo a analogia de que o ar era a peçonha e a bexiga a glândula. Quando questionados, os alunos souberam reportar como ocorria o mecanismo de inoculação da peçonha pelas aranhas e reconhecer as estruturas envolvidas na produção e na inoculação da mesma. A estratégia de se utilizar analogias como forma de trabalhar o conteúdo foi bastante eficaz neste caso, entretanto, ao longo de todo o projeto, o grupo procurou ter cautela ao utilizar esse tipo de abordagem, pois como já discutido por Glynn e colaboradores (1989) e por Duit (1991), as analogias podem levar a equívocos e reforçar compreensões bem distantes das desejadas pelo ensino.

Durante as explicações sobre os efeitos da picada das aranhas e qual soro deve ser tomado, foi levantada uma dúvida interessante por um grupo de alunos. Eles fizeram associações com a peçonha da aranha e a produção de soro, questionando o porquê de se usar o soro se o mesmo é feito da peçonha da aranha, sendo que esta é nociva ao homem. A fim de sanar a dúvida, foi explicado como é produzido o soro antiaracnídico.

Por fim, foi realizada uma atividade lúdica em que as crianças, divididas em dois grupos, competiram respondendo perguntas que tiravam de um envelope e, conforme acertavam, recebiam peças de um quebra-cabeça que formava uma aranha. Praticamente todas as perguntas feitas eram respondidas de forma correta pelas crianças, de forma que os quebracabeças ficaram prontos simultaneamente. A eficiência nas respostas dadas ressaltou que o aprendizado das crianças foi satisfatório.

m. Encerramento: o último encontro consistiu no encerramento das atividades. Houve a exposição do trabalho desenvolvido, ao longo dos seis meses, para os pais dos alunos. Foram reunidas várias atividades realizadas pelas crianças durante toda a extensão. Os pais participaram de um jogo de tabuleiro (o mesmo utilizado na revisão do conteúdo) juntamente com as crianças. Nessa atividade, os alunos ficaram muito empolgados pela oportunidade de mostrar o que haviam aprendido, uma vez que, quando seus pais não sabiam a resposta da pergunta, eles respondiam e explicavam em detalhes tudo o que sabiam a respeito do assunto.

Houve, também, a apresentação de um teatro sobre interações entre aranhas. A dramatização havia sido apresentada durante o desenvolvimento do projeto, mas, dessa vez foi totalmente protagonizada pelos alunos. Além disso, foi feita uma exposição de aranhas fixadas para observação em estereomicroscópio, e à medida que os pais observavam os exemplares, as crianças davam explicações sobre quais estruturas poderiam ser observadas e suas respectivas funções.

Este encontro final foi extremamente significativo para os pais, as crianças, os mediadores e a professora regente. Os pais tiveram a oportunidade de vivenciar as atividades das quais seus filhos haviam participado e de aprender com eles. As crianças, por sua vez, tiveram 
a chance de apresentar o que aprenderam ao longo do projeto de uma forma interativa e dinâmica, evidenciando o quanto estavam entusiasmadas diante desta oportunidade. Para a professora regente e para o grupo PET/Biologia-UFU, foi extremamente gratificante perceber o quanto os jovens haviam progredido durante a execução do projeto, pois eles se lembravam de informações trabalhadas em todas as temáticas abordadas. A partir disso, é possível inferir que a metodologia utilizada no projeto foi eficaz, pois se baseou nos conhecimentos prévios dos sujeitos, buscou reforçar os assuntos trabalhados em cada encontro e manter a coesão entre estes, além de se pautar em atividades lúdicas, interativas e desafiadoras, que estimularam os envolvidos a buscarem o saber.

\section{CONSIDERAÇÕES FINAIS}

A experiência aqui relatada teve um retorno significativo aos mediadores da atividade. Estes, como futuros professores, tiveram a oportunidade de colocar em prática as noções pedagógicas adquiridas na academia. Além disso, puderam ter contato direto com o cotidiano escolar, ampliar seus conhecimentos sobre o grupo das aranhas e vivenciar experiências com Educação Básica e Ensino por Projetos. Por outro lado, a execução dessas atividades comprova o papel da educação por meio de projetos como uma ferramenta facilitadora e otimizadora do processo de ensinoaprendizagem. Esse tipo de abordagem permite que assuntos específicos inseridos ou não nas propostas curriculares formais possam ser trabalhados produtivamente em sala de aula, resultando em uma formação diferenciada. Por meio de projetos dessa natureza, tem-se maior liberdade na escolha, no planejamento, no controle de tempo de execução e na flexibilização dos conteúdos, podendo-se tratar a temática selecionada de maneira mais adequada a cada realidade escolar.

Esta abordagem teve grande relevância, pois permitiu que os alunos entrassem em contato não somente com as aranhas, mas também com a natureza como um todo, já que o estudo partiu de um objeto específico, que foi inserido em um contexto mais amplo, transgredindo e relacionandose com outros fatores, incluindo o próprio homem. Isso permitiu que as crianças percebessem o quão estão interligados os elementos na natureza e a importância de se preservar o ambiente no qual estão inseridas. Além disso, os alunos puderam se informar sobre a importância biológica do grupo das aranhas e a relação do homem com estes organismos. As crianças envolveram-se com o projeto e com o conhecimento trabalhado de tal maneira que propuseram o desenvolvimento de projetos com outras abordagens como insetos, felinos e peixes. Este entusiasmo mostrou que a estratégia da educação por meio de projetos, neste caso, atingiu seus objetivos, despertando o interesse dos alunos para a Ciência, ainda nas séries iniciais da Educação Básica.

O conhecimento científico deve estar intrínseco à realidade educacional das crianças, uma vez que é salutar para o desenvolvimento de cidadãos críticos conscientes, capazes de compreender inteligentemente o mundo em que vivem, bem como serem potenciais contribuidores para a melhoria deste e agentes multiplicadores de tal conhecimento. 


\section{REFERÊNCIAS}

ALMEIDA, R. D. de. Do desenho ao mapa: iniciação cartográfica escolar. São Paulo: Contexto, 2004.

BLACK, P.; ATKIN, J. M. (Org.). Changing the subject: innovations in science, mathematics and technology education. London: OECD \& Routledge, 1996.

BRASIL. Ministério da Educação. Parâmetros Curriculares Nacionais. 1996. Disponível em: $<$ http://www.zinder.com.br/legislacao/pcn-fund.htm>. Acesso em: 20 nov. 2011.

CAMPOS, L. M. L.; BORTOLOTO, T. M.; FELÍCIO, A. K. C. A produção dos jogos didáticos para o ensino de Ciências e Biologia: uma proposta para favorecer a aprendizagem. Caderno dos Núcleos de Ensino, São Paulo, p. 36, 2003.

CUNHA, N. H. S. Brinquedo, desafio e descoberta. 1994. 427f. Tese (Doutorado) - Faculdades Associadas de Ensino, Rio de Janeiro, 1994.

DUIT, R. On the role of analogies and metaphors in learning science. Science Education, New York, n. 75, v. 6, p. 653, 1991.

FERRARESI, A. C. et al. O uso da internet como fonte de pesquisa entre universitários: um estudo de caso. In: ENCONTRO LATINO AMERICANO DE INICIAÇÃO CIENTÍFICA, 13.; ENCONTRO LATINO AMERICANO DE PÓS-GRADUAÇÃO, 9., 2009, Anais... Vale do Paraíba: UNIVAP, 2009, p. 1-6.

GONZAGA et al (Orgs.). Ecologia e comportamento de aranhas. Rio de Janeiro: Interciência, 2007, $400 \mathrm{p}$.

GARDNER, P. L. Students interest in science and technology; In: LERKE, M. et al. (Orgs.). Interests in science and technology education. Kiel: Kiel University, 1985, p. 17.

GILBERT, J. K.; BOULTER, C. J.; ELMER, R. Positioning models in science education and in design and technology education. In: GILBERT J. K.; C. J. BOULTER (Orgs.). Developing models in science education. Dordrecht: Kluwer, 2000.

GLYNN, S. M. et al. Analogical reasoning and problem solving in science textbooks. In: GLOVER, J. A., RONNING, R. R., REYNOLDS, C. R. (Orgs.). A handbook of creativity: assessment, research and theory. New York: Plenum, 1989.

GOMES, R. R.; FRIEDRICH, M. A contribuição dos jogos didáticos na aprendizagem de conteúdos de Ciências e Biologia. In: EREBIO, 1., Rio de Janeiro, 2001. Anais... Rio de Janeiro, 2001, p. 390.

FOELIX, R. F. Biology of Spiders. 2 ed. Oxford: Oxford University Press, 1996, 336 p.

HANSEN, M. F.; PINHEIRO, T. F. Projetos de trabalho e o ensino de ciências. In: ENCONTRO NACIONAL DE PESQUISA EM EDUCAÇÃO EM CIÊNCIAS, 5., 2005. Baurú, Anais... Baurú: UNESP, 2005, p. 3. 
HOERING, A. M.; PEREIRA A. B. As aulas de ciências iniciando pela prática: o que pensam os alunos. Revista da Associação Brasileira de Pesquisa em Educação em Ciências, v. 4, n. 3, p. 24, set./dez., 2004.

KRASILCHIK, M. Ensino de ciências e a formação do cidadão. Em Aberto, Brasília, v. 7, n. 40, p. 59, out./dez., 1988.

KISHIMOTO, T. M. (Org). Jogo, brinquedo, brincadeira e a educação. São Paulo: Cortez, 2000.

LABINAS, A. M.; CALIL, A. M. G. C.; AOYAMA, E. M. Experiências concretas como recurso para o ensino sobre insetos. Revista Ciências Humanas, Taubaté, v. 3, n. 1, p. 98, 2010.

LORENZETTI, L.; DELIZOICOV, D. Alfabetização científica no contexto das séries iniciais. Ensaio, Belo Horizonte, v. 3, n. 1, p. 11, jun. 2001.

MARTINS, I.; GOUVÊA, G.; PICCININI, C. Aprendendo com imagens. Ciência e Cultura, São Paulo, v. 57, n. 4, p. 39, 2005.

MELlO, G. N.; DALlAN, M. C.; GRELlET, V. Projetos como alternativa de ensino e aprendizagem. In: MELLO, G. N. de (Org.). Educação escolar brasileira: o que trouxemos do século XX? São Paulo: Artmed, 2004.

MORÁN, J. M. O vídeo na sala de aula. Comunicação e Educação, São Paulo, v. 2, p. 27-28, 1995.

MOREIRA, M. A. Mapas conceituais e aprendizagem significativa. Revista Galaico- portuguesa de Sociopedagogia e Sociolinguística, Pontevedra, n. 23, p. 87-95, 1988.

OLIVEIRA, L. M. de; VENTURA, P. C. S. A prática da aprendizagem por projetos em três óticas distintas. Educação e tecnologia, Belo Horizonte, v. 10, n. 2, p. 22-28, jul./dez. 2005.

SANT'ANNA, I. M. Por que avaliar? Como avaliar? Critérios e instrumentos. 3.ed. Petrópolis: Vozes, 1998.

SERRANO, R. M. S. M. Conceitos de extensão universitária: um diálogo com Paulo Freire. Disponível em: $<$ http://www.prac.ufpb.br/copac/extelar/atividades/discussao/artigos/conceitos de_extensao_universitaria.pdf $>$. Acesso em: 15 fev. 2012.

WARD, H.; HEWLETT, C.; RODEN, J. Ensino de ciências. Porto Alegre: Artmed, 2010.

Submetido em 3 de maio de 2012.

Aprovado em 27 de agosto de 2012. 